STUDI

FRANCESI

\section{Studi Francesi}

Rivista quadrimestrale fondata da Franco Simone

187 (LXIII | I) | 2019

Varia

JEAN-BAPTISTE AMADIEU, La Littérature française au XIX ${ }^{e}$ siècle mise à l'Index, Les procédures

\title{
Michel Arrous
}

\section{(2) OpenEdition}

Journals

Édition électronique

URL : http://journals.openedition.org/studifrancesi/16422

DOI : $10.4000 /$ studifrancesi. 16422

ISSN : 2427-5856

Éditeur

Rosenberg \& Sellier

Édition imprimée

Date de publication : 1 juillet 2019

Pagination : 162-163

ISSN : 0039-2944

Référence électronique

Michel Arrous, "JEAN-BAPTISTE AMADIEU, La Littérature française au xix siècle mise à I'Index, Les procédures 》. Studi Francesi [En ligne], 187 (LXIII | I) | 2019, mis en ligne le 01 juillet 2019, consulté le 25 janvier 2021. URL : http://journals.openedition.org/studifrancesi/16422 ; DOI : https://doi.org/10.4000/ studifrancesi. 16422

Ce document a été généré automatiquement le 25 janvier 2021.

\section{(c) (i) (9) $\Theta$}

Studi Francesi è distribuita con Licenza Creative Commons Attribuzione - Non commerciale - Non opere derivate 4.0 Internazionale. 


\title{
JEAN-BAPTISTE AMADIEU, La Littérature française au XIXe siècle mise à l'Index, Les procédures
}

\author{
Michel Arrous
}

\section{RÉFÉRENCE}

JEAN-BAPTISTE AMADIEU, La Littérature française au XIXe siècle mise à l'Index, Les procédures,

Paris, Cerf, 2017, 542 pp.

1 Les condamnations civiles des romans pour outrage à la morale publique sont documentées, mais la proscription ecclésiastique l'est beaucoup moins. Ce n'est plus le cas grâce la publication de la première partie de la thèse de J.-B. Amadieu où sont examinées d'un point de vue juridique et historique la pratique et la philosophie de la censure ecclésiastique de la littérature de fiction au xix siècle. Créé dans le but de préserver la foi et les mœurs - les premiers Indices datent de la Réforme -, le célèbre répertoire des ouvrages condamnés par le Saint-Siège a disparu à l'issue du concile Vatican II. Les archives de la Congrégation de l'Index n'ayant été ouvertes qu'en 1998, l'institution est restée longtemps obscure. Si la liste des fictions françaises condamnées est connue, les subtilités et les étapes de la procédure l'étaient beaucoup moins.

De nombreux écrivains ont eu droit à la proscription (le record est détenu par Renan, «la bête noire de l'Index», 14 décrets, devant Michelet, 6), à l'exception de Chateaubriand, Baudelaire, les Goncourt, Paul de Kock, Musset, Loti, Nerval, Rimbaud, Verlaine qui ont échappé à la procédure parce que la Congrégation n'avait pas les moyens de tout examiner ou parce qu'elle pouvait réprouver un livre sans le mentionner dans ses sentences. À cela s'ajoutait le fait que les mises à l'Index tardaient parfois plusieurs années.

3 Le procès de la mise à l'Index est exposé dans la deuxième partie (la première retrace l'évolution de l'Index jusqu'en 1900), de son origine au verdict, sans aucune audition 
préalable de l'auteur. Tout commence par une plainte formulée par un dignitaire ecclésiastique ou un simple laïc qui, à condition d'être justifiée, entraîne la rédaction d'une relation (le votum) sur l'œuvre dénoncée, et la procédure suit son cours. On la résume ainsi: plainte ou dénonciation, consultation, délibération, promulgation, proscription. Sont d'abord étudiées deux dénonciations «certaines»: l'une émanant du fils de J. de Maistre en 1836 contre Chatterton, pour motif politique, mais l'œuvre ne fut pas mise à l'Index quoique jugée immorale et hérétique à cause de sa justification du suicide, et dépourvue de séduction car sans aucun mérite littéraire (ce fut aussi le cas d'Une Larme du diable de Gautier); l'autre rédigée en 1879 par le nonce à Paris et visant L'Assommoir n'eut aucun effet. Vient ensuite le véritable feuilleton des examens d'Eugène Sue qui dura de 1844, pour Les Mystères de Paris, à 1851, pour les Sept Péchés capitaux. Sue fut condamné pour ses théories «socialistes et révolutionnaires», sa haine du clergé, de l'aristocratie et des riches notabilités. En revanche, en 1898-1899, Huysmans, quasiment dénoncé par une critique publique et simultanément recommandé, craignit non sans raisons que La Cathédrale ne fût condamnée suite à la diffusion de la Conversion de M. Huysmans, charge de l'abbé Belleville qui ressemblait fort à une dénonciation. Le rapport d'un consulteur mentionna la "prétendue conversion» de l'auteur de «plusieurs œuvres extrêmement suspectes sur des sujets concernant la foi et les mœurs», mais aucune procédure ne fut engagée contre l'écrivain.

4 Les institutions romaines (secrétairerie d'État, nonciatures) évaluent les dénonciations et agissent, prudemment, en amont de l'Index. Il arrive qu'à Rome on débatte d'une possible dénonciation, comme pour le Testament d'un antisémite de Drumont signalé en 1891 par le nonce à Paris, parce qu'il s'agissait non seulement d'un ouvrage antisémite mais aussi d'une attaque contre le haut clergé français jugé corrompu (y compris le nonce lui-même). En dépit de nombreuses demandes adressées au nonce, aucune dénonciation ne parvint à l'Index; de plus, il était inutile de prononcer une condamnation nominative car l'œuvre, outrageant le clergé, était d'office à l'Index. J.-B. Amadieu cite aussi le cas étonnant de l'auteur se dénonçant lui-même: en 1894, dans la polémique déclenchée par la mise à l'Index de Lourdes, Félix Lacan, professeur à la Sorbonne, publie Pour le Vrai. À Lourdes avec Zola, qu'il dédicace au pape. Est aussi évoquée la possible dénonciation de Lamartine par l'internonce à Paris qui sévit de 1836 à 1843: Mgr Antonio Garibaldi intervint auprès du cardinal Polidori qui jugea dangereux le Voyage en Orient et plus encore Jocelyn, d'où un premier décret contre l'œuvre du poète le 22 septembre 1836, et un second en 1838 contre La Chute d'un ange. Comme dans le cas précédent, Garibaldi avait informé le préfet de l'Index en lui adressant le poème agrémenté de ses commentaires. Garibaldi sera aussi à l'origine des proscriptions de Sand et de Balzac, mais ce n'est qu'en 1863 et 1864 que les deux romanciers seront condamnés pour leurs écrits.

Les consulteurs sont informés par dénonciation, mais aussi parce qu'ils connaissent assez bien la République des lettres. On en a un bel exemple avec Jacques Baillès qui joua un rôle de premier plan dans la censure de la littérature française: sept condamnations générales sur les dix que compte le corpus fictionnel français viennent de ses examens et son influence dura plus de vingt-cinq ans après sa mort. Ce prêtre érudit et ultramontain, évêque de Luçon et consulteur, fut à l'origine en 1863 et 1864 de la proscription des opera omnia de Sand, Soulié, Stendhal (pour Le Rouge et le Noir, mais déjà à l'Index pour Rome, Naples et Florence), E. Feydeau, Champfleury, Murger, Balzac, Zola et des condamnations particulières de Flaubert, Hugo, Michelet, etc. Avec Baillès, on a affaire à un champion ou à un virtuose de l'Index qui publiera en 1866 une 
Congrégation de l'Index mieux connue et vengée, somme par laquelle il réplique aux griefs des «gallicans» contre la Congrégation alors fort mal connue.

6 Le chapitre 3 - «Le votum sur l'œuvre» - expose les normes canoniques et l'usage du votum dont se chargeait un rapporteur membre de la Congrégation de l'Index, parfois un secrétaire ou un cardinal. Recension de l'œuvre, le votum regroupait en principe des observations fondées sur des exemples répréhensibles (passages contraires à la foi ou aux mœurs), mais il contenait parfois des appréciations littéraires. Parmi les vota mentionnés, celui sur Spiridion qui signale une religion nouvelle et une doctrine hétérodoxe, et ceux concernant les Dumas dont les œuvres donnèrent du travail aux consulteurs, lesquels conclurent en 1862 et 1863 à l'immoralité et à l'irréligion. À noter que Madame de Chamblay eut droit à deux vota; de même pour Les Mystères de Paris, mais avec deux résultats différents et non sans de sensibles contradictions: absence de condamnation en 1845 , mise à l'Index en 1852 et censure de toutes les œuvres. S'il arrive que certains censeurs pratiquent le résumé dans sa forme la plus réduite ou la sélection fragmentaire, d'autres tendent à l'exhaustivité, tel Polidori qui examina méticuleusement tout le Voyage en Orient de Lamartine, alors que Baillès estime inutile l'examen complet des Misérables et se limite à quelques exemples pour Mademoiselle La Quintinie, de même Vercellone en 1866 pour Le Confesseur de l'abbé Michon.

On suit dans le chapitre 4 - «Le verdict de mise à l'Index» - les étapes de la procédure jusqu'à la proscription publique formulée dans l'intitulé de la clausule (par exemple, omnia fabulae amatoriae, pour les histoires d'amour impur, lascif ou obscène: Sue, les Dumas - Le Comte de Monte-Cristo est jugé inoffensif par le consulteur De Ferrari-, Soulié, Sand, etc.). À la fin du siècle, alors que l'Index n'est plus ignoré du grand public, comment lire un ouvrage interdit sans violer le droit canonique? Chateaubriand disait qu'à Rome "pour quelques bajocchi on obtient la permission de lire, en sûreté de conscience, l'ouvrage défendu»... Il est vrai que le Saint-Siège ou les évêques accordent de nombreuses dispenses aux lecteurs avertis qui voulaient lire la Vie de Jésus de Renan ou La Religion naturelle de Jules Simon, et pour les œuvres inscrites au programmes officiel de l'enseignement secondaire ou supérieur. Les fidèles pouvaient disposer d'ouvrages expurgés publiés par des éditeurs catholiques qui bénéficiaient de clauses dérogatoires (pour Eugénie Grandet et Le Médecin de campagne), ou qui souhaitaient donner des éditions critiques de Rousseau, Montesquieu ou Pascal. Les fidèles français ont-ils strictement observé les décisions censoriales ecclésiastiques?

8 Quelle a été la réception de l'Index en France au XIX ${ }^{e}$ siècle ? Dans la troisième partie J.B. Amadieu esquisse quelques réponses, notamment pour la première moitié du siècle et la crise de 1850-1853 et la «querelle des classiques» lancée par l'abbé Gaume. Son Ver rongeur des sociétés modernes (1851) dénonçait l'influence du paganisme sur la littérature et celle du romantisme accusé de prolonger l'impiété de la littérature classique, thèse contestée par Dupanloup qui ferrailla contre Gaume, Veuillot et l'opposition ultramontaine, jusqu'à ce qu'une encyclique mette fin à la dispute. La contestation de l'Index devient marginale et ne réapparaîtra que peu avant Vatican II. Quant à son autorité dans la seconde moitié du siècle, force est de constater que si les catholiques de France la connaissent, elle n'a guère de portée, à la différence d'autres pays européens ou du Canada. Bien que quelques évêques veillent à les faire respecter, le public catholique français continuera à ignorer les prescriptions de l'Index, ou ne les connaîtra bien plus tard que par le truchement des Romans à lire et romans à proscrire de l'abbé Bethléem (1932) dont J.-Y. Mollier a retracé «l'impossible mission». Quant aux 
auteurs, aucun ne s'inquiète vraiment de sentences que la plupart d'entre eux ignorent. Flaubert n'en dit rien; Balzac, pourtant reçu par le pape qui avait signé les décrets de proscription de ses œuvres, n'en parle pas davantage; Lamartine ne s'émeut guère de la mise à l'index du Voyage en Orient; Sand se moque de la décision du Saint-Père ( $\$ \mathrm{Si}$ le cher homme savait combien cela m'est égal!»). En revanche, plutôt flatté de quatre décrets de prohibition, et après le décret du 19 septembre 1894 qui condamna Lourdes, Zola espéra une audience de Léon XIII, à laquelle d'ailleurs il renonça. Il craignait que la mise à l'Index ne diminuât les ventes du livre. Citons encore Bloy, une des cibles de l'abbé Bethléem, qui a marqué son mépris pour «les congrégations de simoniaques dont le Siège apostolique est inexprimablement déshonoré», et qui donc se «fiche absolument de l'Index et des décrets de cette racaille».

9 Bien des procédures dénonçant les déviances paraissent désinvoltes et expéditives, et bien des examens sont bâclés ou ne respectent pas la procédure ordinaire, ou bien le sens de l'œuvre n'est pas compris. Il arrive, sans qu'on sache pourquoi, que les cardinaux ne suivent pas la demande de condamnation; enfin, l'Index a été contesté au sein de l'Église par les "gallicans». Toutefois, des critères prédominent: l'immoralité d'une bonne part du théâtre et des romans français, les religiosités romantiques et les croyances apostates (matérialisme, panthéisme, progressisme chrétien), les idées politiques.

10 Jusqu'à la publication de cette thèse, les dix-neuviémistes qui ont feuilleté quelquesunes des éditions de l'Index, particulièrement celle de 1900, ne disposaient que des travaux d'Asztrik datant des années 1930, de ceux de Guillemin sur Jocelyn (1936), alors que les archives de l'Index et du Saint-Office étaient encore inaccessibles, et des relevés de J.M. de Bujanda (2002). De 2004 à 2015 les articles publiés par J.-B. Amadieu révélaient quelques aspects ignorés du fonctionnement de l'Index; désormais, la première partie de ses recherches étant publiée, les règles et procédures de l'Index sont claires et les textes de censure de la plupart des romantiques accessibles. Chateaubriand avait vu dans l'Index un des «témoins des anciens temps au milieu des temps nouveaux»; Zola, soixante-dix ans avant la disparition du fameux catalogue, s'exclamait: «quelle extraordinaire et lamentable bastille du passé, que cet Index vieilli, caduc, tombé en enfance!» 